\title{
California Verbal Learning Test, Children's Version
}

National Cancer Institute

\section{Source}

National Cancer Institute. California Verbal Learning Test, Children's Version. NCI

Thesaurus. Code C62620.

Provides a short, individually administered assessment of the strategies and processes involved in learning and recall of verbal material. Assessment is made in the context of an everyday event. It measures both recall and recognition of words over a number of trials and has been found to be sensitive to memory deficits resulting from a variety of neurological conditions. It is designed for ages 5 through 16 . 